G. D. Tan · M. J. Neville $\cdot$ E. Liverani .

S. M. Humphreys · J. M. Currie · L. Dennis •

B. A. Fielding $\cdot$ F. Karpe

\title{
The in vivo effects of the Pro12Ala PPARy2 polymorphism on adipose tissue NEFA metabolism: the first use of the Oxford Biobank
}

Received: 1 June 2005 / Accepted: 11 August 2005 / Published online: 17 December 2005

C) Springer-Verlag 2005

\begin{abstract}
Aims/hypothesis: To investigate the phenotypic effects of common polymorphisms on adipose tissue metabolism and cardiovascular risk factors, we set out to establish a biobank with the unique feature of allowing a prospective recruit-by-genotype approach. The first use of this biobank investigates the effects of the peroxisome proliferatoractivated receptor- $\gamma$ (PPAR $\gamma$ ) Pro12Ala polymorphism on integrative tissue-specific physiology. We hypothesised that Ala12 allele carriers demonstrate greater adipose tissue metabolic flexibility and insulin sensitivity. Materials and methods: From a comprehensive population register, subjects were recruited into a biobank, which was genotyped for the Pro12Ala polymorphism. Twelve healthy male Ala12 carriers and 12 matched Pro12 homozygotes underwent detailed physiological phenotyping using stable isotope techniques, and measurements of blood flow and arteriovenous differences in adipose tissue and muscle in response to a mixed meal containing $\left[1,1,1{ }^{13} \mathrm{C}\right]$ tripalmitin. Results: Of 6,148 invited subjects, 1,072 were suitable for inclusion in the biobank. Among Pro12 homozygotes, insulin sensitivity correlated with HDL-cholesterol concentrations, and inversely correlated with blood pressure, apolipoprotein B, triglyceride and total cholesterol concentrations. Ala12 carriers showed no such correlations. In the meal study, Ala12 carriers had lower plasma NEFA concentrations, higher adipose tissue and muscle blood flow, and greater insulin-mediated postprandial hormonesensitive lipase suppression along with greater insulin sensitivity than Pro12 homozygotes. Conclusions/interpretation: This study shows that a recruit-by-genotype approach is feasible and describes the biobank's first application, providing tissue-specific physiological find-
\end{abstract}

G. D. Tan $(\bowtie) \cdot$ M. J. Neville · E. Liverani · S. M. Humphreys · J. M. Currie - L. Dennis - B. A. Fielding - F. Karpe Oxford Centre for Diabetes, Endocrinology and Metabolism, Churchill Hospital, University of Oxford, Oxford OX3 7LJ, UK

e-mail: garry.tan@oxlip.ox.ac.uk

Tel.: +44-1865-857289

Fax: $+44-1865-857217$ ings consistent with the epidemiological observation that the PPAR $\gamma$ Ala12 allele protects against the development of type 2 diabetes.

Keywords Genetics · Insulin sensitivity · Obesity · Peroxisome proliferator-activated receptors . PPAR $\gamma 2$ - Pro12Ala polymorphism . Single nucleotide polymorphism - Type 2 diabetes

Abbreviations apoB: apolipoprotein B - HOMA-IR: homeostasis model assessment for insulin resistance . HSL: hormone-sensitive lipase - OBB: Oxford Biobank · PPAR $\gamma$ : peroxisome proliferator-activated receptor- $\gamma$

\section{Introduction}

The gene for peroxisome proliferator-activated receptor- $\gamma$, $P P A R G$, plays a key role in insulin resistance and type 2 diabetes, as well as adipocyte differentiation and lipid metabolism [1]. The Pro12Ala polymorphism of the PPAR $\gamma 2$ isoform has an Ala12 allele frequency of around 0.12 in Caucasians [2]. Epidemiological studies have shown an association of the Pro12 allele with an increased risk of developing type 2 diabetes, with a populationattributable risk of $25 \%$ [3, 4]. In vivo in humans, Ala12 allele carriers are more insulin-sensitive than Pro12 homozygotes [5-9]. Although PPAR $\gamma$ activation by thiazolidinediones leads to insulin sensitisation, in vitro studies of the polymorphism have shown that the substitution of Ala for Pro results in reduced transcriptional activity of $P P A R G$ $[5,10]$.

The role of the Pro12Ala polymorphism in the development of obesity is less clear. A meta-analysis suggested that Ala12 carriers were more likely to have a high BMI than Pro12 homozygotes, an effect only identifiable among subjects with a BMI greater than $27 \mathrm{~kg} / \mathrm{m}^{2}$ [11]. Thus, Ala12 carriers appear to be heavier than Pro12 homozygotes, yet have a lower risk of developing type 2 diabetes. However, the mechanism underlying this apparent paradox is unclear. 
Subjects with type 2 diabetes treated with the PPAR $\gamma$ agonist rosiglitazone exhibit a similar unexpected dissociation between weight and insulin sensitivity: increasing weight is associated with an increase in insulin sensitivity. However, some weight gain may be due to fluid retention, as well as increasing fat mass. The exact mechanisms of insulin sensitisation are unclear, although we have previously documented changes in fatty acid metabolism in subjects treated with rosiglitazone [12].

We hypothesised that Ala12 carriers are more efficient in sequestering fatty acids in adipose tissue, and demonstrate greater metabolic flexibility in the storage and mobilisation of NEFAs in the postprandial period. Such a mechanism would increase insulin sensitivity and decrease the likelihood of developing type 2 diabetes, and would also be consistent with the increased adipose tissue mass observed in Ala12 carriers.

Such a complex genotype-phenotype relationship cannot be identified from stored fasting plasma. A useful approach could be to start by identifying carriers of certain genotypes from large cohort studies (i.e. genotyping many individuals). From such a large database of volunteers, closely matched subjects, differing as far as possible only in their genotype of interest, could be prospectively recruited into a study for detailed phenotyping. This recruit-by-genotype approach would allow the study of the influences of common genetic variants on metabolism. Prospective recruitment allows close baseline matching, along with comprehensive characterisation of the phenotype of interest, and adequately powered studies. Such biobanks have been set up to investigate other complex intermediate phenotypes [13,14], but never before for insulin resistance and type 2 diabetes.

We therefore set out to establish a biobank, known as the Oxford Biobank (OBB), to allow the prospective investigation of genotype-phenotype relationships in adipose tissue and human metabolism. The OBB included DNA, anthropometric and biochemical data of healthy subjects taken at random from the general population. Recruited subjects would be willing to participate in detailed metabolic phenotyping in order to investigate insulin resistance and type 2 diabetes.

The possible functional impact of the PPAR $\gamma 2$ Pro12Ala polymorphism, along with its high prevalence in the Caucasian population, made it a promising candidate for detailed tissue-specific metabolic phenotyping using the recruit-by-genotype approach. As PPARG is highly expressed in adipose tissue [15] and as subcutaneous abdominal adipose tissue is the major source of circulating NEFA in humans [16], we chose to phenotype subcutaneous abdominal adipose tissue function in Pro12 homozygotes and Ala12 allele carriers, with particular emphasis on fatty acid and triglyceride metabolism in vivo, in order to test our hypothesis that the Ala12 allele carriers would handle NEFA metabolism more efficiently in adipose tissue and skeletal muscle. These inferences have already been drawn, but have never been tested directly at the level of adipose tissue.

\section{Subjects and methods}

\section{Oxford Biobank}

Using the comprehensive population register maintained by the UK National Health Service, an age-stratified random sample of 30- to 50-year-old men and women from Oxfordshire (total population 615,200 [17]) was selected. Exclusion criteria included mental or physical ill health, alcohol- or drug-related problems, and abnormal biochemical data as determined by history, examination, routine blood tests and information obtained from each subject's primary care physician. Subjects attended a screening visit at the Clinical Research Unit, where blood tests were performed, including plasma glucose, insulin and triglyceride analysis. Basic anthropometric data were recorded, including weight, height and skinfold measurements. DNA was stored from the visit and consent obtained to allow subsequent genotyping for current and future genes of potential importance in adipose tissue metabolism. Samples were genotyped for the Pro12Ala polymorphism by PCR sequence-specific amplification, as previously described [18], using the allele-specific primers: 5'-TGAAG GAATCGCTTTCTGG-3' and 5'-TGAAGGAATCGCTT TCTGC- $3^{\prime}$ and the consensus primer $5^{\prime}$-GTCACCGGC GAGACAG-3' to generate an allele-specific product of 357 nucleotides. The products were then visualised on a $1 \%$ agarose gel containing ethidium bromide.

\section{Pro12Ala meal studies}

\section{Subjects}

From the OBB register, 24 healthy non-diabetic subjects were recruited by genotype. Twelve Ala12 heterozygotes and 12 matched Pro12 homozygotes were selected. No Ala12 homozygotes were used because no suitable subjects were available to participate. As smoking can affect insulin sensitivity, only non-smoking subjects were recruited. The study was approved by the Oxfordshire Research Ethics Committee and all subjects gave their written informed consent.

To assess the interaction of weight and genotype, we deliberately set out to recruit some subjects who were of normal weight and some subjects who were overweight into both genotype groups. Of the 24 subjects, 12 were overweight (six Pro12 homozygotes and six Ala12 carriers) and 12 were of normal weight (six Pro12 homozygotes and six Ala12 carriers). Overweight subjects had a BMI greater than $28.5 \mathrm{~kg} / \mathrm{m}^{2}$ and were in the highest quartile of subjects in the OBB by weight. Normal-weight subjects had a BMI less than $25.5 \mathrm{~kg} / \mathrm{m}^{2}$ and were in the lower half of subjects in the OBB by weight.

The 24 selected subjects attended the Clinical Research Unit for a full-day metabolic investigation. Vigorous exercise and alcohol were avoided for $24 \mathrm{~h}$ and food for 
$10 \mathrm{~h}$ before the study. During the study day, arteriovenous differences in metabolites across adipose tissue and skeletal muscle were measured, along with tissue blood flow. Body fat was measured by bioimpedence using a Bodystat 500 (Bodystat, Douglas, UK).

\section{Metabolic investigation protocol}

Recording arteriovenous differences across adipose tissue and skeletal muscle enabled the measurement of differences between the composition of venous blood draining a particular tissue and arterialised blood, thus reflecting that tissue's metabolic activity. Inclusion of tissue blood flow into the calculations allows quantification of net metabolic activity. On the day of the study, serial blood samples were taken in the fasting state and for $6 \mathrm{~h}$ after metabolic provocation with a standardised mixed meal, a technique we have used elsewhere [12].

Arterialised blood was obtained from a vein draining a heated hand. Venous blood from muscle was taken retrogradely from a vein draining the deep structures of the forearm. Venous blood from adipose tissue was obtained from the superficial epigastric vein, as described previously [19]. This vein drains subcutaneous abdominal adipose tissue with negligible contribution from other tissues [20]. Oxygen saturation and ultrasonography were used to confirm adequate siting of the cannulae. Blood samples were taken simultaneously from all three sites. To prevent contamination of the blood from the forearm vein with blood from the hand, a wrist cuff was inflated to $200 \mathrm{mmHg}$ for $3 \mathrm{~min}$ before taking samples. Two sets of baseline blood samples were taken $30 \mathrm{~min}$ apart. Patients then consumed a meal of a fat emulsion, skimmed milk and Rice Krispies (Kellogg Company, Manchester, UK) containing $40 \mathrm{~g}$ fat and $40 \mathrm{~g}$ carbohydrate and $600 \mathrm{mg}$ $\left[1,1,1-{ }^{13} \mathrm{C}\right]$ tripalmitin. Further blood samples were taken for $6 \mathrm{~h}$ after the meal.

Plasma triglyceride, NEFA, glucose and insulin and blood glycerol concentrations were measured as described previously [21]. Adiponectin was measured using ELISA (Linco, St Charles, MO, USA).

The postprandial increase in ${ }^{13} \mathrm{C}$ in the circulation was derived from the $\left[1,1,1-{ }^{13} \mathrm{C}\right]$ tripalmitin in the meal. NEFAs and triglycerides were extracted from fasting and postprandial arterialised plasma samples for gas chromatography and gas chromatography-combustion-isotope ratio mass spectrometry. Enrichments of $\left[{ }^{13} \mathrm{C}\right]$ palmitate in plasma NEFA and triglyceride fractions were measured. The results were multiplied by the concentrations of palmitate-NEFA and palmitate-triglyceride, respectively to give the concentrations of the tracer in these fractions, as previously described [21]. The rate of appearance in expired air of ${ }^{13} \mathrm{CO}_{2}$ from $\left[{ }^{13} \mathrm{C}\right]$ palmitate was measured using gas chromatography-isotope ratio mass spectrometry, providing an index of whole-body fatty acid oxidation.

Subcutaneous abdominal adipose tissue blood flow was measured by ${ }^{133} \mathrm{Xe}$ washout [22]. Forearm muscle blood flow was assessed by strain-gauge plethysmography [23].
Statistical analyses, power and calculations

Adipose tissue blood flow was calculated as described previously [22]. Arteriovenous and venoarterial differences

Table 1 Anthropometric, biochemical and haemodynamic data of subjects in the Oxford Biobank

\begin{tabular}{|c|c|}
\hline \multicolumn{2}{|l|}{ Number of subjects } \\
\hline Male & 550 \\
\hline Female & 524 \\
\hline \multicolumn{2}{|l|}{ Frequency of Ala12 allele } \\
\hline Male (349 genotyped) & 0.136 \\
\hline Female (420 genotyped) & 0.135 \\
\hline \multicolumn{2}{|l|}{ Age (years) } \\
\hline Male & $42(36-45)$ \\
\hline Female & $41(35-47)$ \\
\hline \multicolumn{2}{|l|}{ Body mass index $\left(\mathrm{kg} / \mathrm{m}^{2}\right)$} \\
\hline Male & $26.0(23.9-28.7)$ \\
\hline Female & $24.4(22.2-28.4)$ \\
\hline \multicolumn{2}{|l|}{ Waist circumference $(\mathrm{cm})$} \\
\hline Male & $92(85-99)$ \\
\hline Female & $78(72-87)$ \\
\hline \multicolumn{2}{|l|}{ Hip circumference (cm) } \\
\hline Male & $100(96-104)$ \\
\hline Female & $100(94-106)$ \\
\hline \multicolumn{2}{|l|}{ Weight (kg) } \\
\hline Male & $82.6(75.3-91.8)$ \\
\hline Female & $67.0(60.3-76.5)$ \\
\hline \multicolumn{2}{|l|}{ Height (m) } \\
\hline Male & $178(174-183)$ \\
\hline Female & $165(161-169)$ \\
\hline \multicolumn{2}{|l|}{ NEFA $(\mu \mathrm{mol} / \mathrm{l})$} \\
\hline Male & $450(332-598)$ \\
\hline Female & $535(393-704)$ \\
\hline \multicolumn{2}{|l|}{ Glucose (mmol/l) } \\
\hline Male & $5.27(5.01-5.56)$ \\
\hline Female & $5.00(4.76-5.29)$ \\
\hline \multicolumn{2}{|l|}{ Insulin (pmol/1) } \\
\hline Male & $58(41-87)$ \\
\hline Female & $51(37-75)$ \\
\hline \multicolumn{2}{|l|}{ Triglyceride (mmol/l) } \\
\hline Male & $1.23(0.88-1.69)$ \\
\hline Female & $0.90(0.66-1.20)$ \\
\hline \multicolumn{2}{|l|}{ Cholesterol (mmol/l) } \\
\hline Male & $5.50(4.88-6.19)$ \\
\hline Female & $5.29(4.75-6.03)$ \\
\hline \multicolumn{2}{|l|}{ HDL-cholesterol (mmol/l) } \\
\hline Male & $1.22(1.05-1.40)$ \\
\hline Female & $1.47(1.25-1.71)$ \\
\hline \multicolumn{2}{|c|}{ Systolic blood pressure (mmHg) } \\
\hline Male & $123(116-130)$ \\
\hline Female & $112(104-120)$ \\
\hline \multicolumn{2}{|c|}{ Diastolic blood pressure (mmHg) } \\
\hline Male & $80(74-86)$ \\
\hline Female & $74(69-81)$ \\
\hline
\end{tabular}

Values are median (interquartile range) 
in metabolite concentrations were calculated. Absolute flux was calculated as the product of the arteriovenous or venoarterial difference and adipose tissue blood flow [19]. Lipoprotein lipase rate of action in vivo was calculated from triglyceride removal across each tissue [19]. The rate of action of hormone-sensitive lipase (HSL) in adipose tissue in vivo (i.e. the rate of adipose tissue lipolysis) was calculated from the total adipose tissue glycerol release after subtraction of lipoprotein lipase rate of action [19].

The study was powered to detect a $12.5 \%$ difference in fasting NEFA output from adipose tissue, with a power of $90 \%$ at a statistical significance level of 0.05 .

Data were analysed using SPSS for Windows v10 (SPSS UK, Chertsey, UK) and statistical significance was set at $p<0.05$ for all tests. Variables are presented as median (interquartile range) unless otherwise stated. Repeated

a
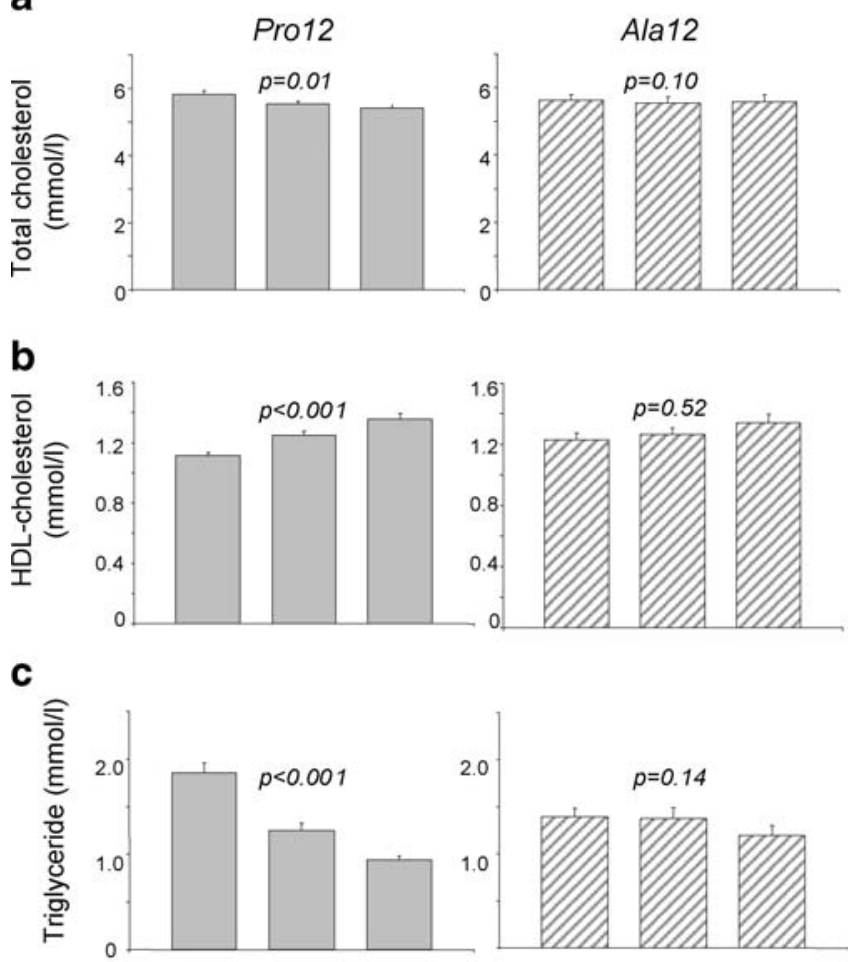

d

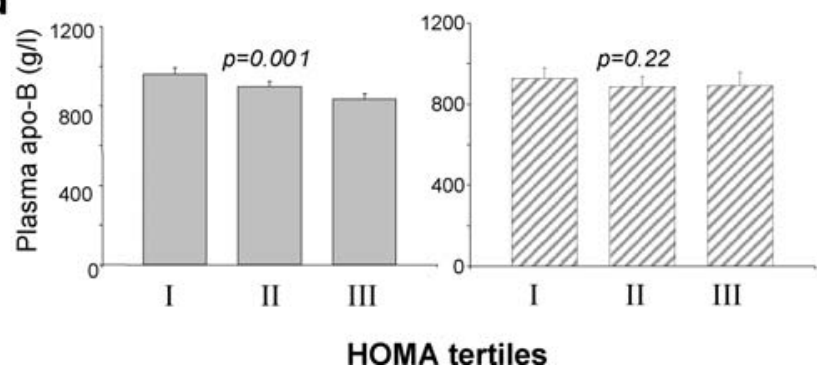

Fig. 1 The Oxford Biobank: effect of the Pro12Ala genotype on metabolic parameters according to insulin sensitivity in men. Plasma total cholesterol (a), HDL-cholesterol (b), triglyceride (c) and apoB (d) concentrations of subjects in the Oxford Biobank, divided according to genotype and tertile of insulin sensitivity (I to III in rising order of sensitivity) within the genotype. The $p$ values are for trend of change between tertiles of insulin sensitivity measures ANOVA was used to identify time effects, drug effects and time by drug interactions. AUCs were compared using Wilcoxon signed rank tests.

\section{Results}

\section{Results of Oxford Biobank}

To date, 6,148 subjects have been invited to participate in the OBB register, and recruitment is ongoing; 1,835 subjects $(30 \%)$ responded to the invitation letter. Of these 1,835 subjects, $1,115(61 \%)$ attended for screening and 1,072 of them $(96 \%)$ were considered suitable for inclusion in the OBB database. To date, 769 (72\%) (349 male) have been genotyped for the PPAR $\gamma 2$ Pro12Ala polymorphism. Of those genotyped, 573 were homozygous for Pro12 (258 male), 184 were heterozygous ( 87 male) and 12 were

Table 2 Characteristics of subjects in the Pro12Ala meal provocation study

\begin{tabular}{|c|c|c|}
\hline & & $p$ value \\
\hline \multicolumn{3}{|l|}{ Number of subjects } \\
\hline Pro12 homozygotes & 12 men & \\
\hline Ala12 carriers & 12 men & \\
\hline Age (years) & & 0.51 \\
\hline Pro12 homozygotes & $47.5(45.8-48.8)$ & \\
\hline Ala12 carriers & $47.0(42.8-50.3)$ & \\
\hline Body mass index $\left(\mathrm{kg} / \mathrm{m}^{2}\right)$ & & 0.83 \\
\hline Pro12 homozygotes & $27.7(24.5-31.5)$ & \\
\hline Ala12 carriers & $27.2(24.7-31.3)$ & \\
\hline Fasting insulin (pmol/l) & & 0.38 \\
\hline Pro12 homozygotes & $48.8(36.0-68.8)$ & \\
\hline Ala12 carriers & $46.7(35.1-64.9)$ & \\
\hline Fasting glucose (mmol/l) & & 0.42 \\
\hline Pro12 homozygotes & $5.14(4.88-5.39)$ & \\
\hline Ala12 carriers & $5.09(4.83-5.40)$ & \\
\hline Total cholesterol (mmol/l) & & 0.25 \\
\hline Pro12 homozygotes & $5.43(4.84-6.09)$ & \\
\hline Ala12 carriers & $5.44(4.88-6.31)$ & \\
\hline Fasting triglyceride $(\mathrm{mmol} / \mathrm{l})$ & & 0.90 \\
\hline Pro12 homozygotes & $0.99(0.70-1.33)$ & \\
\hline Ala12 carriers & $1.06(0.81-1.44)$ & \\
\hline HDL-cholesterol (mmol/l) & & 0.77 \\
\hline Pro12 homozygotes & $1.34(1.15-1.57)$ & \\
\hline Ala12 carriers & $1.36(1.17-1.59)$ & \\
\hline Plasma apoB (g/l) & & 0.50 \\
\hline Pro12 homozygotes & $810(658-994)$ & \\
\hline Ala12 carriers & $802(687-1,000)$ & \\
\hline Systolic blood pressure (mmHg) & & 0.67 \\
\hline Pro12 homozygotes & $116(107-125)$ & \\
\hline Ala12 carriers & $115(108-124)$ & \\
\hline Diastolic blood pressure $(\mathrm{mmHg})$ & & 0.42 \\
\hline Pro12 homozygotes & $75(70-82)$ & \\
\hline Ala12 carriers & $77(71-83)$ & \\
\hline
\end{tabular}

Values are median (interquartile range) 
homozygous for Ala12 (four male). Thus the Ala12 allele frequency was 0.135 . The genotype frequencies of the polymorphism were in Hardy-Weinberg equilibrium $(p=0.32)$. Anthropometric, biochemical and haemodynamic data of subjects recruited into the OBB are presented in Table 1.

Among men, Pro12 homozygotes showed the expected correlation between insulin resistance, assessed by homeostasis model assessment for insulin resistance (HOMA-IR), and lipid parameters (plasma triglyceride concentrations, $p<0.001$; total cholesterol concentrations, $p=0.01$; and plasma apoB concentrations, $p=0.001)$. As expected, insulin resistance correlated negatively with HDL-cholesterol concentrations $(p<0.001)$ among the Pro12 homozygotes. Surprisingly, insulin sensitivity among male Ala12 carriers did not correlate with any of the lipid parameters (triglycerides, $p=0.14$; total cholesterol $p=0.10$; apoB, $p=0.22$; HDL-cholesterol, $p=0.52$ ). These data are presented in Fig. 1, where subjects are divided into tertiles of insulin sensitivity (assessed by HOMA-IR). Among women, lipid parameters correlated with insulin sensitivity, irrespective of genotype (data not shown).

The genotype-specific relationship between insulin sensitivity and features of the metabolic syndrome extended beyond biochemical parameters. Systolic and diastolic blood pressures in males correlated with insulin resistance in Pro12 homozygotes (systolic, $p=0.001$; diastolic, $p<0.0001$ ), but not in Ala12 carriers (systolic, $p=0.75$; diastolic, $p=0.38$ ).

Results of Pro12Ala meal studies

\section{Subjects}

The characteristics of the 24 subjects (12 Pro12 homozygotes and 12 Ala12 carriers) are presented in Table 2. The six obese Pro12 homozygotes had a BMI of $31.6 \mathrm{~kg} /$ $\mathrm{m}^{2}$ (31.3-32.4), whilst the six overweight Ala12 carriers had a BMI of 31.5 (30.8-32.2). The BMI of the six normal weight Pro12 homozygotes was $24.5 \mathrm{~kg} / \mathrm{m}^{2}$ (23.7-24.8), whilst that of the six normal weight Ala12 carriers was $24.6 \mathrm{~kg} / \mathrm{m}^{2}$ (24.2-24.9). There was no difference in body fat percentage, waist or hip measurements, fasting lipid measurements and blood pressure between the Pro12 homozygotes and Ala12 carriers. Unless otherwise stated, there was no difference between the findings of the lean and obese subgroups.

\section{Glucose and insulin}

As shown in Fig. 2, fasting plasma glucose and insulin concentrations were identical between the groups (fasting glucose concentrations: Pro12 homozygotes, $5.49 \mathrm{mmol} / 1$ [5.18-5.74] vs Ala12 carriers, $5.54 \mathrm{mmol} / 1$ [5.29-6.13], $p=0.28$; fasting insulin concentrations: Pro12 homozygotes, $92 \mathrm{pmol} / 1$ [76-130], Ala12 carriers, 100 pmol/1 [64$115], p=0.23)$. The obese subjects in each group were more insulin-resistant than the lean subjects, based on fasting
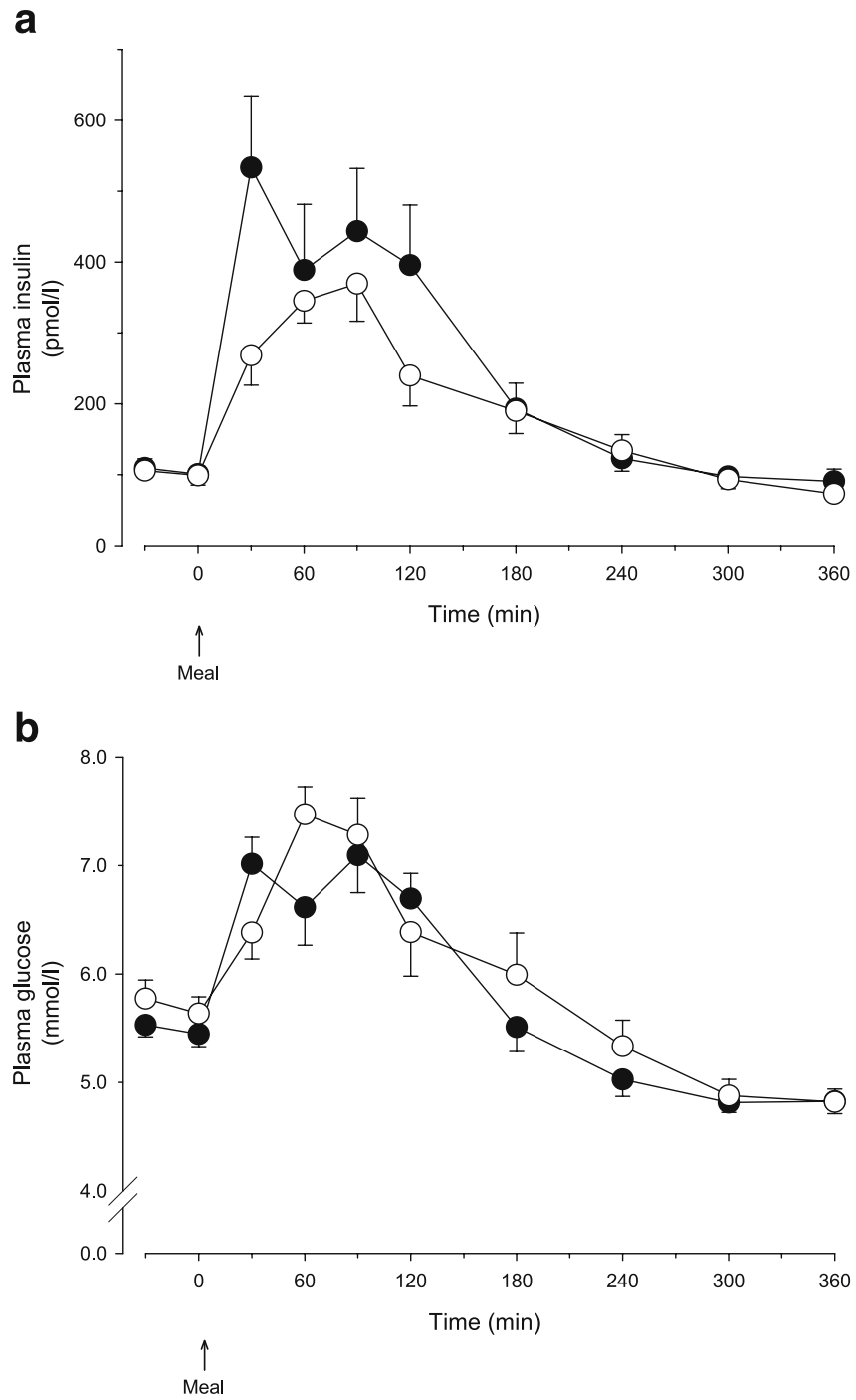

Fig. 2 Pro12Ala meal provocation study. Plasma insulin (a) and glucose (b) concentrations in response to a mixed meal (given at time 0) in Pro12 homozygotes $(\bullet)$ and Ala12 carriers (०). Glucose: $p=0.23$ (fasting), $p=0.004$ (postprandial) (a); insulin: $p=0.28$ (fasting), $p=0.35$ (postprandial) (b)

insulin and glucose concentrations and HOMA calculations (data not shown).

Postprandial glucose concentrations were the same in the Ala12 and Pro12 groups $(p=0.35)$. In contrast, insulin concentrations were significantly lower in the postprandial period in Ala12 carriers than in Pro12 homozygotes $(p=0.004)$.

Glucose uptake by forearm muscle and adipose tissue was the same in the Pro12 and Ala12 groups (Pro12 homozygotes, $0.51 \mu \mathrm{mol} / \mathrm{min}$ per $100 \mathrm{~g}$ tissue [0.34-0.81] vs Ala12 carriers, $0.67 \mu \mathrm{mol} / \mathrm{min}$ per $100 \mathrm{~g}$ tissue [0.450.73] [time-averaged AUC], $p=0.97$ ).

\section{NEFA}

Ala12 carriers had lower fasting and postprandial NEFA concentrations $(-12.5 \%, p=0.05)$ (Fig. 3a). NEFA release 
from subcutaneous abdominal adipose was not different between the groups (Fig. 3b). The Pro12 homozygotes showed a rather constant uptake of NEFA across the forearm, whereas the Ala12 group showed a significantly

a

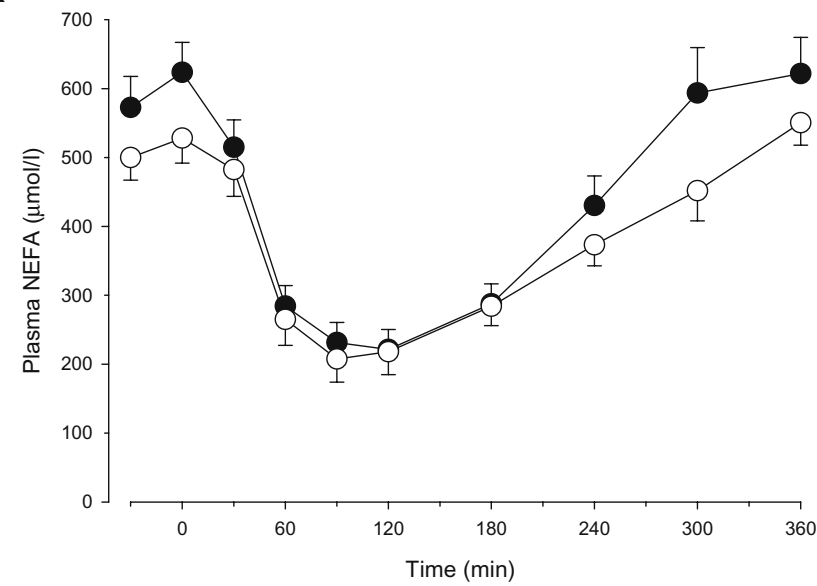

b

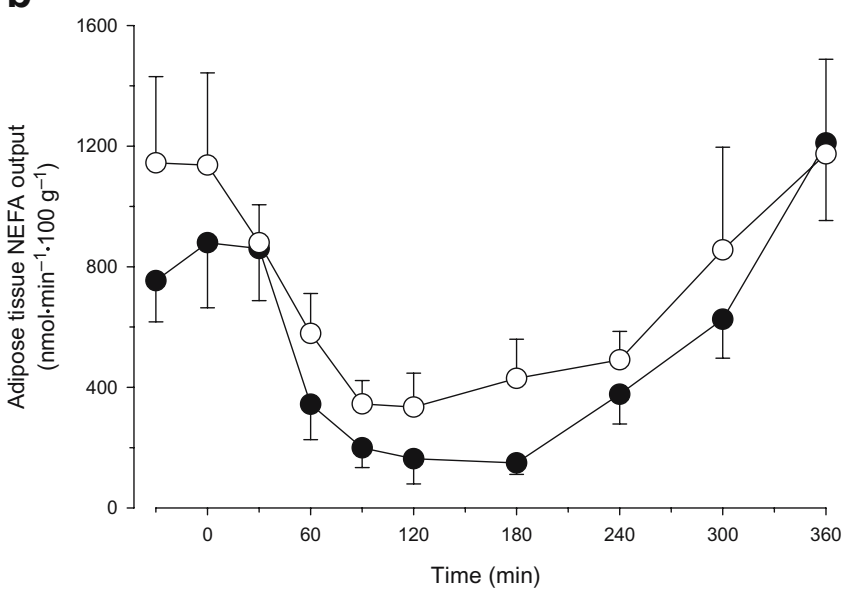

C

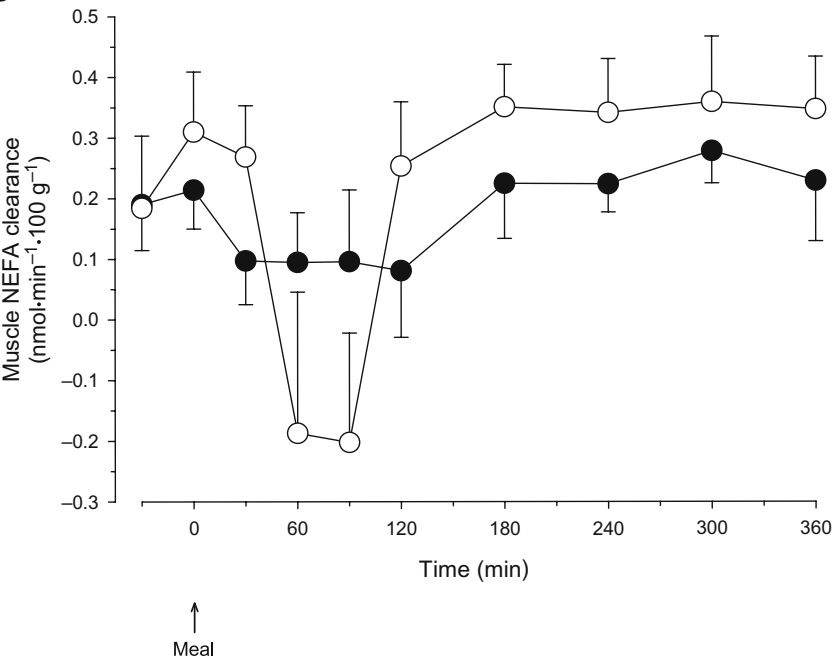

Fig. 3 Pro12Ala meal provocation study. NEFA metabolism in response to a mixed meal (given at time 0) in Pro12 homozygotes (•) and Ala12 carriers ( $($ ). a Plasma NEFA concentrations, $\mathrm{p}=0.05$. b NEFA output from subcutaneous abdominal adipose tissue, $\mathrm{p}=0.92$. c NEFA clearance from muscle, $p<0.01$

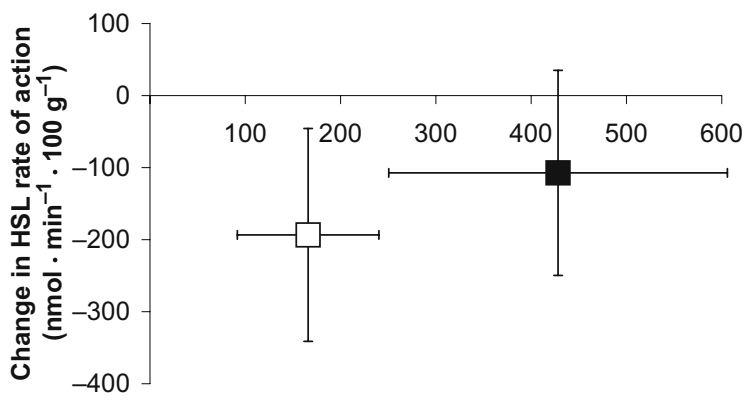

Change in plasma insulin

(pmol/l)

Fig. 4 Pro12Ala meal provocation study. Change in plasma insulin concentrations and change in HSL suppression $30 \mathrm{~min}$ after a mixed meal (given at time 0) in Pro12 homozygotes ( - ) and Ala12 carriers (口). $95 \%$ CIs are shown

decreased uptake of NEFA at the time of peak insulinaemia (Fig. 3c).

Hormone-sensitive lipase in adipose tissue

Figure 4 demonstrates the relationship between the increase in postprandial insulin concentrations (in the first 30 min after the meal), and the postprandial suppression of adipose tissue HSL rate of action (in the first $30 \mathrm{~min}$ after the meal), using bars showing the $95 \%$ CI. In the first $30 \mathrm{~min}$, the insulin-induced suppression of HSL was significant after the meal in the Ala12 carriers, but the change was not significantly different from baseline (zero) in the Pro12 homozygotes. This is an important finding as it reflects differences in one of the most insulin-sensitive processes in adipose tissue, namely suppression of HSL activity, and implies that the Ala12 carriers had considerably greater insulin sensitivity in the early suppression of lipolysis. However, the overall HSL rate of action did not differ between the two groups $(p=0.81)$.

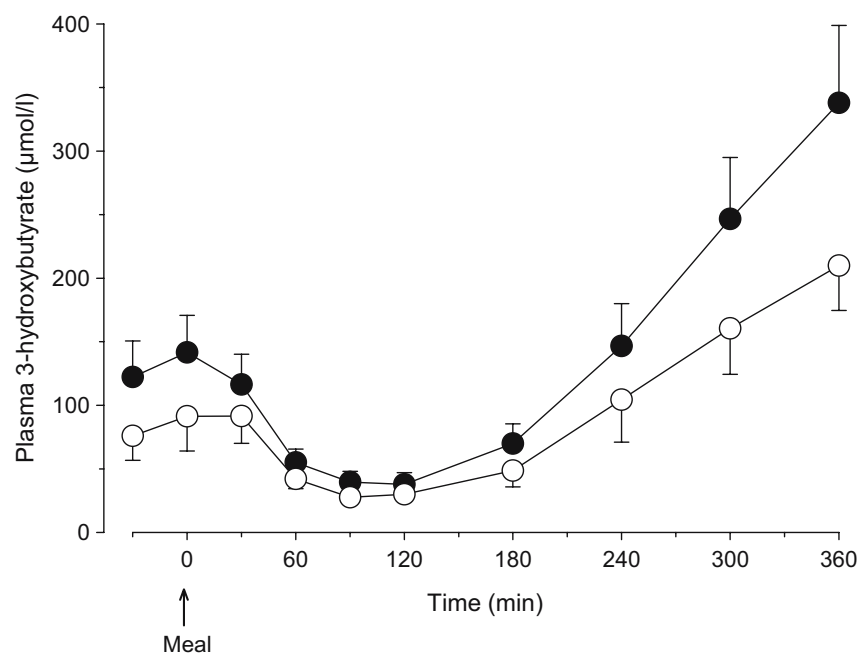

Fig. 5 Pro12Ala meal provocation study. Plasma 3-hydroxybutyrate concentrations in response to a mixed meal (given at time 0 ) in Pro12 homozygotes $(\bullet)$ and Ala12 carriers ( $(\circ) . p=0.05$ 


\section{3-Hydroxybutyrate}

Plasma concentrations of 3-hydroxybutyrate, a reflection of hepatic fatty acid oxidation, followed a similar time course (Fig. 5) to plasma NEFA and were also lower in the Ala12 carriers than in Pro12 homozygotes $(90 \pm 18$ vs $133 \pm$ $19 \mu \mathrm{mol} / 1$ [mean $\pm \mathrm{SEM}$ ] [time-averaged AUC], $p=0.05$ ).

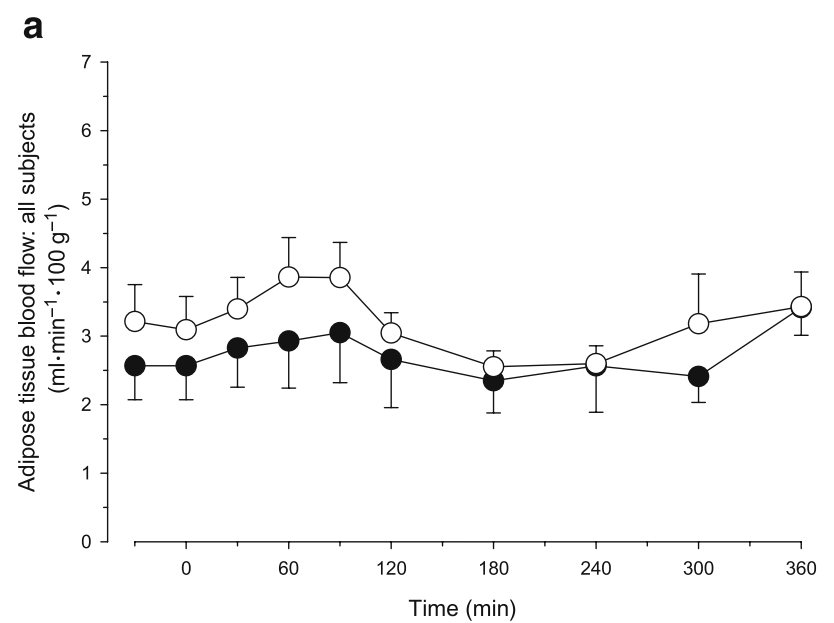

b

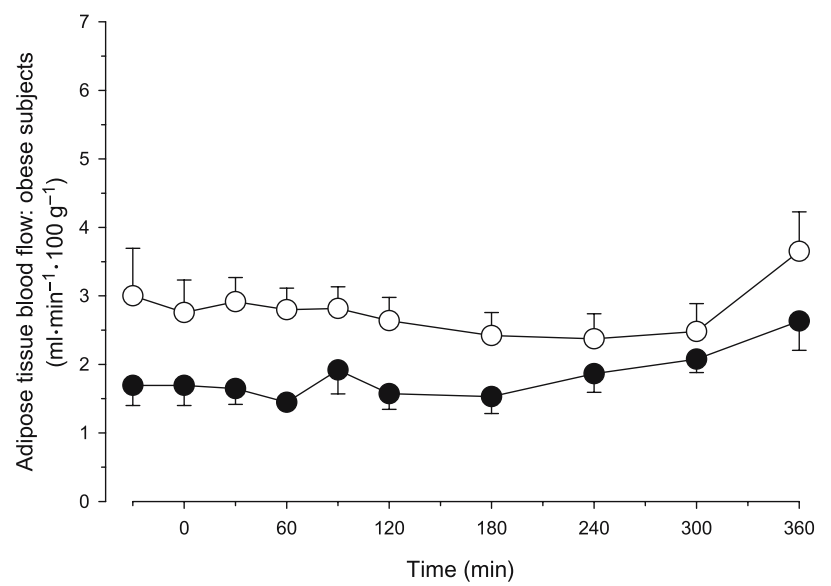

C

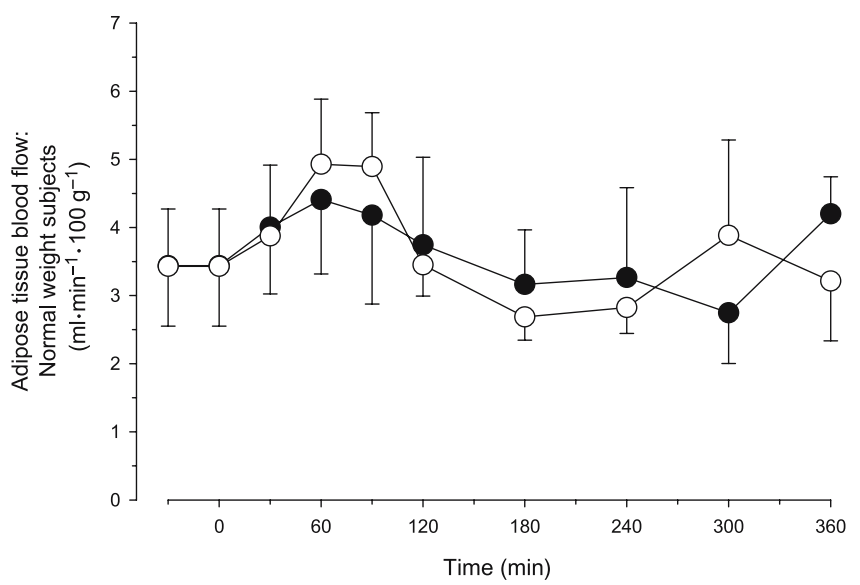

Fig. 6 Pro12Ala meal provocation study. Blood flow in response to a mixed meal (given at time 0 ) in Pro12 homozygotes $(\bullet)$ and Ala12 carriers (०). Adipose tissue blood flow is shown for all subjects, $p=0.06$ (a), for obese subjects, $p=0.03$ (b) and for normal-weight

\section{Triglycerides}

Both fasting and postprandial plasma triglyceride concentrations were similar between the groups (data not shown).

Triglyceride removal in adipose tissue $(p=0.86)$ (data not shown) and forearm muscle (data not shown, $p=0.22$ ) did not differ between Pro12 homozygotes and Ala12 carriers.

d

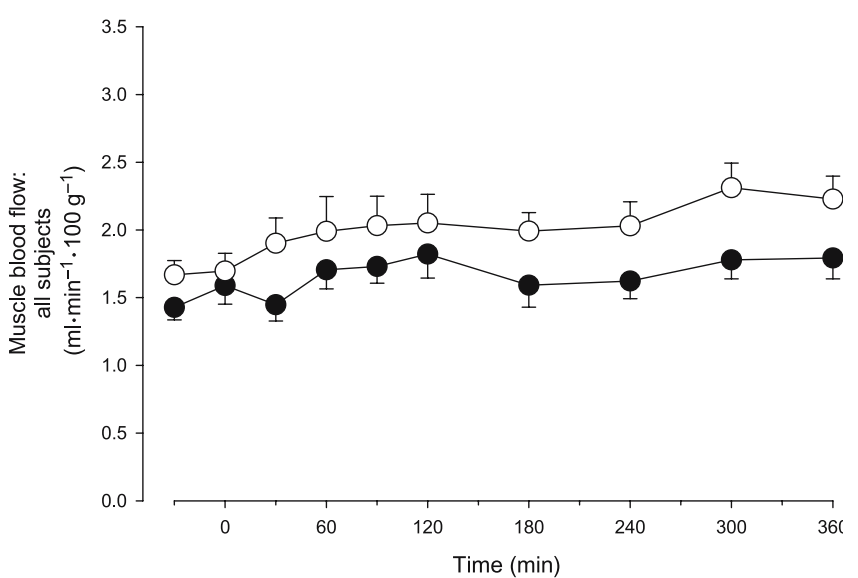

e

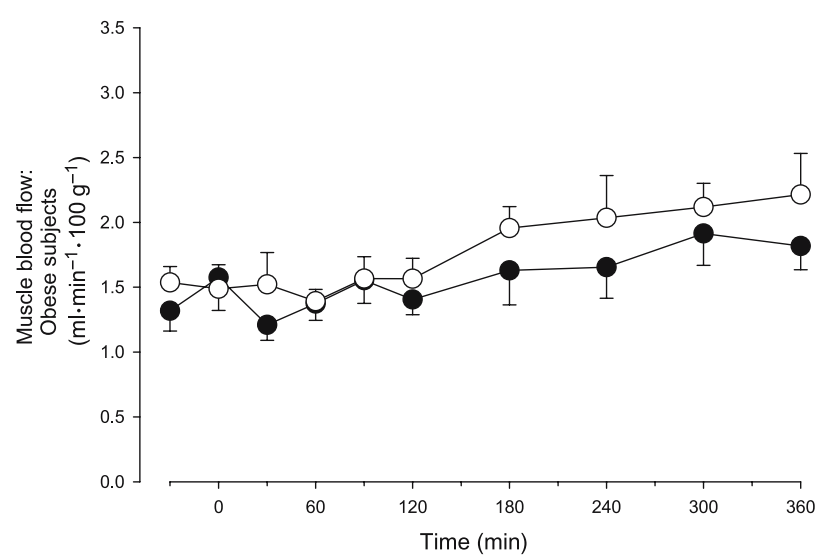

f

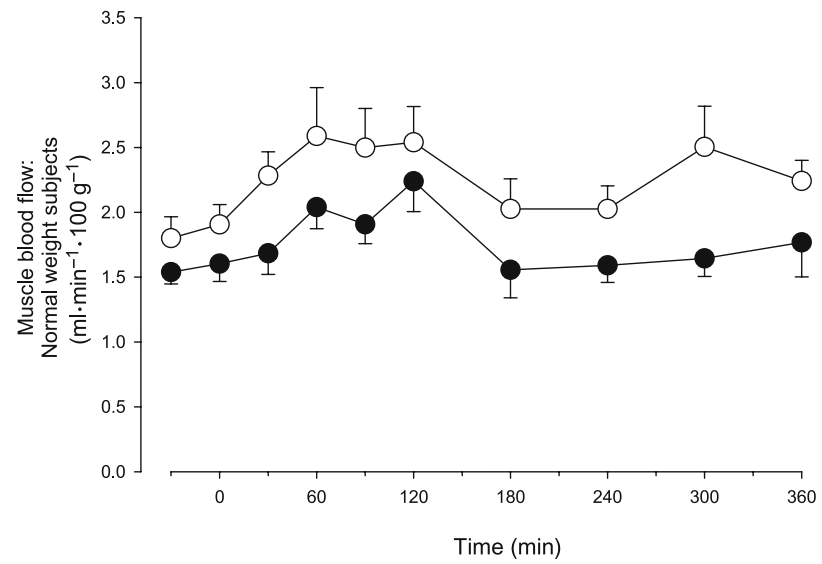

subjects, $p=0.70$ (c). Forearm muscle blood flow is shown for all subjects, $p=0.03$ (d), for obese subjects, $p=0.30$ (e) and for normalweight subjects, $p=0.04$ (f) 


\section{Stable isotopes}

To quantify the proportion of fatty acids derived from the meal, we measured concentrations of $\left[1-{ }^{13} \mathrm{C}\right]$ palmitic acid in the triglyceride fraction and NEFA fraction. $\left[{ }^{13} \mathrm{C}\right]$ Palmitic acid concentrations increased postprandially in the triglyceride fraction (data not shown), and also in the NEFA fraction (data not shown), as would be expected after a meal containing labelled triglycerides. Notably, the rise in $\left[1-{ }^{13} \mathrm{C}\right]$ palmitic acid concentrations in both the NEFA and the triglyceride fraction were the same in both the Ala12 carriers and the Pro12 homozygotes.

The rate of appearance of exhaled ${ }^{13} \mathrm{CO}_{2}$ from $\left[{ }^{13} \mathrm{C}\right]$ palmitate did not differ between the Pro12 homozygotes and Ala12 carriers.

\section{Adiponectin}

Fasting plasma adiponectin concentrations were not different between Ala12 carriers and Pro12 homozygotes (mean \pm SEM, $6.5 \pm 1.0$ vs $6.9 \pm 0.9 \mu \mathrm{g} / \mathrm{ml}, p=0.70$ ).

\section{Blood flow}

Adipose tissue blood flow was higher in the Ala12 group compared with the Pro12 group $(+17 \%)$, but this did not reach statistical significance $(p=0.06)$ (Fig. 6a). This difference in adipose tissue blood flow was solely due to higher adipose tissue blood flow in overweight Ala12 subjects compared with overweight Pro 12 subjects $(+49 \%$, $p=0.03$ ) (Fig. 6b); no difference could be seen between Ala12 and Pro12 subjects in the normal weight groups $(+0 \%, p=0.70)$ (Fig. $6 \mathrm{c})$.

Forearm muscle blood flow was also higher in the Ala12 than in the Pro12 group $(+22 \%, p=0.03)$ (Fig. 6d). This difference in muscle blood flow was only seen in normalweight Ala12 subjects compared with normal-weight Pro12 subjects $(+29 \%, p=0.04)$ (Fig. 6e); no difference could be seen between overweight Ala12 and overweight Pro12 subjects $(+14 \%, p=0.30)$ (Fig. $6 f)$.

\section{Discussion}

This is one of the first studies to use a recruit-by-genotype approach to allow the prospective investigation of genotype-phenotype relationships in adipose tissue metabolism. Here, we show that, for investigation of the impact of a gene that is important in insulin resistance, such an approach was both feasible and successful.

Individuals recruited into the OBB should be considered as a highly motivated subset, although they are similar to those recruited into other large population-based studies (e.g. [24]). However, because the genotype frequencies of the polymorphism were in Hardy-Weinberg equilibrium, it is likely that a representative sample of the population has been recruited here.

Although there were no overall metabolic differences between Pro12 homozygotes and Ala12 carriers (Table 2), the metabolic response to the presence of insulin resistance did differ, suggesting a gene-environment interaction. Using the OBB register, insulin sensitivity showed the expected correlations with plasma triglyceride, apoB and HDL-cholesterol concentrations among male Pro12 homozygotes, whereas the corresponding correlations were absent among male Ala12 carriers (Fig. 2). Thus, male Ala12 carriers seemed to be protected against the metabolic consequences of insulin resistance. Such findings prompted us to metabolically characterise the Pro12Ala polymorphism in greater detail.

The meal study of the Pro12Ala polymorphism recruited age-, sex- and BMI-matched subjects from the OBB register. Despite this close matching, we observed significant differences in a number of physiological variables. We found that Ala12 carriers had lower NEFA concentrations in the fasting and late postprandial periods than the Pro12 homozygotes. The use of a mixed meal as a physiological stimulus, rather than insulin clamp techniques, allows assessment of normal physiological variations in diurnal NEFA concentrations. Such elevation of plasma NEFA concentrations may play an important role in the pathogenesis of type 2 diabetes [25-27].

Postprandial excursions of plasma insulin concentrations were lower in Ala12 carriers, despite identical postprandial plasma glucose concentrations. This occurred despite identical fasting concentrations of insulin and glucose. This can only be interpreted as a sign of increased insulin sensitivity in the Ala12 carriers, which is consistent with the findings of other groups $[5-9,28]$.

The suppression of HSL activity in adipose tissue is an insulin-sensitive process, and occurs as insulin concentrations rise in the postprandial period. Thus, the measurement of HSL rate of action gives an estimate of the tissue-specific insulin sensitivity. Adipose tissue HSL in Ala12 carriers was suppressed rapidly in the postprandial period, whereas the postprandial suppression HSL of Pro12 homozygotes was not significantly different from baseline, despite higher insulin concentrations than in the Ala12 carriers (Fig. 4). By measuring systemic labelled glycerol concentrations during a clamp, Stumvoll and colleagues found that Ala12 carriers suppressed their systemic concentrations of glycerol at lower insulin concentrations than Pro12 homozygotes [28]. The mechanism of this is likely to be mediated by changes in HSL activity in adipose tissue, as shown by the tissue-specific measurements in our study.

One study found no difference in fasting NEFA concentrations between Pro12 homozygotes and Ala12 carriers [29]. However, by careful phenotyping of matched subjects, we did find subtle differences in NEFA metabolism between Pro12 homozygotes and Ala12 carriers. Fasting and postprandial NEFA concentrations were lower in Ala12 carriers, despite unchanged NEFA release from 
subcutaneous abdominal adipose tissue. Could a difference in the generation of NEFAs from dietary triglycerides account for the difference in plasma NEFA concentrations observed? By measuring plasma concentrations of stable isotopes derived from the meal containing $\left[1,1,1-{ }^{13} \mathrm{C}\right]$ tripalmitin, we were able to assess the generation of NEFAs from dietary triglycerides; there was no difference between Ala12 carriers and Pro12 homozygotes. This use of stable isotopes addressed the question of whether there was an increased spillover of fatty acids from the intravascular lipolysis of chylomicron triglycerides. These data did not support that possibility.

Tissue blood flows were also affected by the Pro12Ala polymorphism. Adipose tissue blood flow tended to be higher in Ala12 carriers compared with the Pro12 homozygotes. This difference was due to higher adipose tissue blood flow in the obese Ala12 subgroup. We have previously shown a strong relationship between adipose tissue blood flow and insulin sensitivity [30], and these findings support the notion that the adipose tissue of Ala12 carriers is more insulin-sensitive than that of Pro12 homozygotes. There was a small but statistically significant increase in forearm muscle blood flow in the Ala12 carriers, but this was accounted for by differences between the lean subgroups. We have previously shown that increasing insulin sensitivity by PPAR $\gamma$ activation increases adipose tissue blood flow, but does not affect muscle blood flow [12]. Thus, the explanation for the observed increase in muscle blood flow among lean Ala12 carriers is unclear. PPAR $\gamma$ activation is known to modify vascular responsiveness in vivo [31-33] and in vitro [34-36], but the effect of PPAR $\gamma 2$ Pro12Ala polymorphism has never been assessed previously. Thus, Ala12 carriers appear to have a constitutively higher blood flow compared with Pro12 homozygotes. Such genotype-specific difference in nutritive blood flow is likely to impact on the metabolic function of adipose tissues and muscle $[37,38]$.

Some authors have suggested that the Pro12Ala polymorphism influences adipose tissue distribution, finding that Pro12 homozygotes have centrally distributed fat, whilst Ala12 carriers have increased peripheral fat [39, 40]. In the OBB database, skinfold and waist:hip measurements were not significantly different between the Prol2 homozygotes and Ala12 allele carriers, irrespective of sex.

Removal of NEFAs from the circulation occurs in muscle and liver. Here, we show that Ala12 carriers modulate their muscle NEFA clearance from fasted to fed and back to the fasted state (Fig. 3c). However, the muscle NEFA uptake of Pro12 homozygotes shows little change at the time of peak postprandial insulinaemia. This flexibility of NEFA metabolism across the forearm muscle suggests a genotypespecific difference in skeletal muscle NEFA handling. At first glance, such an effect is difficult to reconcile, considering that the Pro12Ala polymorphism is specific to PPAR $\gamma 2$, whilst it is PPAR $\gamma 1$ which is found in skeletal muscle [41]. It is therefore likely that the effect in skeletal muscle is secondary to changes in systemic NEFA con- centrations or other metabolic mediators. Such metabolic flexibility reflects the ability of tissues to switch from the use of one fuel to another and has been suggested as a more important marker of insulin sensitivity than absolute concentrations of metabolites [42, 43].

3 -Hydroxybutyrate is generated by the liver from fatty acid oxidation and indirectly reflects NEFA handling in the liver; this was lower in Ala12 carriers than in Pro12 homozygotes. Whether this is the primary reason for the difference in plasma NEFA concentrations, or whether the lower NEFA oxidation in the liver merely reflected lower plasma NEFA concentrations is unclear. Interestingly, the measure of whole-body fatty acid oxidation, the rate of appearance in expired air of ${ }^{13} \mathrm{CO}_{2}$ from $\left[{ }^{13} \mathrm{C}\right]$ palmitate, did not differ between Ala12 carriers and Pro12 homozygotes. Thus, the lower rate of fatty acid oxidation in the liver of Ala12 carriers may have been compensated for by a lower rate of fatty acid oxidation in the skeletal muscle.

Adiponectin is known to increase fatty acid oxidation and thus might be expected to influence NEFA concentrations. However, reports of the differences in plasma adiponectin concentrations between Ala12 carriers and Pro12 homozygotes are conflicting [44-46]. The differences are perhaps explained by the race of the subjects studied: among Japanese subjects, Ala12 carriers have lower plasma adiponectin concentrations than Pro12 homozygotes [44, 45], whilst among Caucasian subjects there is no difference between Pro12 homozygotes and Ala12 carriers [46]. Our study of a Caucasian population is consistent with these findings.

The use of a mixed meal as the physiological stimulus to assess the effects of metabolic provocation has benefits compared with non-physiological insulin doses, as occurs when hyperinsulinaemic clamps are used. Many studies look at the association between measures of fasting insulin sensitivity (e.g. HOMA-IR) and the Pro12Ala polymorphism. We can see that in response to the physiological stimulus of a mixed meal, the main effects on insulin sensitisation are observed in the postprandial period. Another advantage of using a physiological stimulus of a meal is that the transition from the fed to the fasted state allows us to explore features of metabolic flexibility, an important characteristic lost in insulin resistance $[42,43]$. There were subtle differences in metabolism between healthy Pro12 homozygotes and Ala12 carriers, including differences in plasma NEFA concentrations and tissue blood flow, along with increased insulin sensitivity. These tissue-specific physiological findings are consistent with the epidemiological observation that the PPAR $\gamma$ Ala12 allele protects against the development of type 2 diabetes.

Acknowledgements G. D. Tan was supported by the Medical Research Council and F. Karpe is a Wellcome Trust Senior Clinical Fellow. This project was supported by a Wellcome Trust Integrative Physiology Award. The Oxford Biobank was established through a research grant from the British Heart Foundation and is now being further developed by funding from EC Framework 6 (MolPAGE consortium LSHG-CT-2004). 


\section{References}

1. Kersten S, Desvergne B, Wahli W (2000) Roles of PPARs in health and disease. Nature 405:421-424

2. Yen CJ, Beamer BA, Negri C et al (1997) Molecular scanning of the human peroxisome proliferator activated receptor gamma (hPPAR gamma) gene in diabetic Caucasians: identification of a Pro12Ala PPAR gamma 2 missense mutation. Biochem Biophys Res Commun 241:270-274

3. Altshuler D, Hirschhorn JN, Klannemark M et al (2000) The common PPARgamma Pro12Ala polymorphism is associated with decreased risk of type 2 diabetes. Nat Genet 26:76-80

4. Ardlie KG, Lunetta KL, Seielstad M (2002) Testing for population subdivision and association in four case-control studies. Am J Hum Genet 71:304-311

5. Deeb SS, Fajas L, Nemoto M et al (1998) A Pro12Ala substitution in PPARgamma2 associated with decreased receptor activity, lower body mass index and improved insulin sensitivity. Nat Genet 20:284-287

6. Ek J, Andersen G, Urhammer SA et al (2001) Studies of the Pro12Ala polymorphism of the peroxisome proliferator-activated receptor-gamma2 (PPAR-gamma2) gene in relation to insulin sensitivity among glucose tolerant Caucasians. Diabetologia 44:1170-1176

7. Koch M, Rett K, Maerker E et al (1999) The PPARgamma2 amino acid polymorphism Pro 12 Ala is prevalent in offspring of Type II diabetic patients and is associated to increased insulin sensitivity in a subgroup of obese subjects. Diabetologia 42:758-762

8. Hara K, Okada T, Tobe K et al (2000) The Pro12Ala polymorphism in PPAR gamma2 may confer resistance to type 2 diabetes. Biochem Biophys Res Commun 271:212-216

9. Buzzetti R, Petrone A, Ribaudo MC et al (2004) The common PPAR-gamma2 Pro12Ala variant is associated with greater insulin sensitivity. Eur J Hum Genet 12:1050-1054

10. Masugi J, Tamori Y, Mori H, Koike T, Kasuga M (2000) Inhibitory effect of a proline-to-alanine substitution at codon 12 of peroxisome proliferator-activated receptor-gamma 2 on thiazolidinedione-induced adipogenesis. Biochem Biophys Res Commun 268:178-182

11. Masud S, Ye S (2003) Effect of the peroxisome proliferator activated receptor-gamma gene Pro12Ala variant on body mass index: a meta-analysis. J Med Genet 40:773-780

12. Tan GD, Fielding BA, Currie JM et al (2005) The effects of rosiglitazone on fatty acid and triglyceride metabolism in type 2 diabetes. Diabetologia 48:83-95

13. Sarkkinen E, Korhonen M, Erkkila A, Ebeling T, Uusitupa M (1998) Effect of apolipoprotein E polymorphism on serum lipid response to the separate modification of dietary fat and dietary cholesterol. Am J Clin Nutr 68:1215-1222

14. Lundahl B, Hamsten A, Karpe F (2002) Postprandial plasma ApoB-48 levels are influenced by a polymorphism in the promoter of the microsomal triglyceride transfer protein gene. Arterioscler Thromb Vasc Biol 22:289-293

15. Auboeuf D, Rieusset J, Fajas L et al (1997) Tissue distribution and quantification of the expression of mRNAs of peroxisome proliferator-activated receptors and liver $\mathrm{X}$ receptor-alpha in humans: no alteration in adipose tissue of obese and NIDDM patients. Diabetes 46:1319-1327

16. Guo Z, Hensrud DD, Johnson CM, Jensen MD (1999) Regional postprandial fatty acid metabolism in different obesity phenotypes. Diabetes 48:1586-1592

17. Office for National Statistics. http://www.oxfordshire.gov.uk/ index/living/facts/population_statistics/midyear-population.htm, Accessed 6 January 2005

18. Welsh K, Bunce M (1999) Molecular typing for the MHC with PCR-SSP. Rev Immunogenet 1:157-176

19. Frayn KN, Coppack SW (2001) Assessment of white adipose tissue metabolism by measurement of arteriovenous differences. Methods Mol Biol 155:269-279
20. Frayn KN, Coppack SW, Humphreys SM, Whyte PL (1989) Metabolic characteristics of human adipose tissue in vivo. Clin Sci (Lond) 76:509-516

21. Evans K, Burdge GC, Wootton SA, Clark ML, Frayn KN (2002) Regulation of dietary fatty acid entrapment in subcutaneous adipose tissue and skeletal muscle. Diabetes 51:2684 2690

22. Larsen OA, Lassen NA, Quaade F (1966) Blood flow through human adipose tissue determined with radioactive xenon. Acta Physiol Scand 66:337-345

23. Rådegran G (1999) Limb and skeletal muscle blood flow measurements at rest and during exercise in human subjects. Proc Nutr Soc 58:887-898

24. Williams DR, Wareham NJ, Brown DC et al (1995) Undiagnosed glucose intolerance in the community: the Isle of Ely Diabetes Project. Diabet Med 12:30-35

25. Paolisso G, Tataranni PA, Foley JE, Bogardus C, Howard BV, Ravussin E (1995) A high concentration of fasting plasma nonesterified fatty acids is a risk factor for the development of NIDDM. Diabetologia 38:1213-1217

26. Charles MA, Eschwege E, Thibult N et al (1997) The role of non-esterified fatty acids in the deterioration of glucose tolerance in Caucasian subjects: results of the Paris Prospective Study. Diabetologia 40:1101-1106

27. Pankow JS, Duncan BB, Schmidt MI et al (2004) Fasting plasma free fatty acids and risk of type 2 diabetes: the Atherosclerosis Risk in Communities Study. Diabetes Care 27:77-82

28. Stumvoll M, Wahl HG, Loblein K et al (2001) Pro12Ala polymorphism in the peroxisome proliferator-activated receptor-gamma2 gene is associated with increased antilipolytic insulin sensitivity. Diabetes 50:876-881

29. Temelkova-Kurktschiev T, Hanefeld M, Chinetti G et al (2004) Ala12Ala genotype of the peroxisome proliferator-activated receptor gamma2 protects against atherosclerosis. J Clin Endocrinol Metab 89:4238-4242

30. Karpe F, Fielding BA, Ilic V, Macdonald IA, Summers LK, Frayn KN (2002) Impaired postprandial adipose tissue blood flow response is related to aspects of insulin sensitivity. Diabetes 51:2467-2473

31. Avena R, Mitchell ME, Nylen ES, Curry KM, Sidawy AN (1998) Insulin action enhancement normalizes brachial artery vasoactivity in patients with peripheral vascular disease and occult diabetes. J Vasc Surg 28:1024-1031

32. Murakami T, Mizuno S, Ohsato K et al (1999) Effects of troglitazone on frequency of coronary vasospastic-induced angina pectoris in patients with diabetes mellitus. Am J Cardiol 84:92-94, A8

33. Sidhu JS, Cowan D, Kaski JC (2004) Effects of rosiglitazone on endothelial function in men with coronary artery disease without diabetes mellitus. Am J Cardiol 94:151-156

34. Arima S, Kohagura K, Takeuchi K et al (2002) Biphasic vasodilator action of troglitazone on the renal microcirculation. J Am Soc Nephrol 13:342-349

35. Song J, Walsh MF, Igwe R et al (1997) Troglitazone reduces contraction by inhibition of vascular smooth muscle cell Ca2+ currents and not endothelial nitric oxide production. Diabetes 46:659-664

36. Peuler JD, Warfield RK, Phelps LE (2004) Attenuation by 4 aminopyridine of delayed vasorelaxation by troglitazone. Metabolism 53:147-152

37. Clark MG, Colquhoun EQ, Rattigan $S$ et al (1995) Vascular and endocrine control of muscle metabolism. Am J Physiol 268: E797-E812

38. Baron AD, Clark MG (1997) Role of blood flow in the regulation of muscle glucose uptake. Annu Rev Nutr 17:487499

39. Gonzalez Sanchez JL, Serrano Rios M, Fernandez Perez C, Laakso M, Martinez Larrad MT (2002) Effect of the Pro12Ala polymorphism of the peroxisome proliferator-activated receptor gamma-2 gene on adiposity, insulin sensitivity and lipid profile in the Spanish population. Eur J Endocrinol 147:495-501 
40. Kim KS, Choi SM, Shin SU, Yang HS, Yoon Y (2004) Effects of peroxisome proliferator-activated receptor-gamma 2 Pro12Ala polymorphism on body fat distribution in female Korean subjects. Metabolism 53:1538-1543

41. Auwerx J (1999) PPARgamma, the ultimate thrifty gene. Diabetologia 42:1033-1049

42. Storlien L, Oakes ND, Kelley DE (2004) Metabolic flexibility. Proc Nutr Soc 63:363-368

43. Kelley DE (2002) Skeletal muscle triglycerides: an aspect of regional adiposity and insulin resistance. Ann N Y Acad Sci 967:135-145
44. Yamamoto Y, Hirose H, Miyashita K et al (2002) PPAR (gamma)2 gene Pro12Ala polymorphism may influence serum level of an adipocyte-derived protein, adiponectin, in the Japanese population. Metabolism 51:1407-1409

45. Takata N, Awata T, Inukai K et al (2004) Pro12Ala substitution in peroxisome proliferator-activated receptor gamma 2 is associated with low adiponectin concentrations in young Japanese men. Metabolism 53:1548-1551

46. Thamer C, Machicao F, Fritsche A, Stumvoll M, Häring H (2003) No influence of the PPARgamma2 Pro12Ala genotype on serum adiponectin concentrations in healthy Europeans. Metabolism 52:798; author reply 798-799 